\title{
Evaluation of the Exposure to Electromagnetic Fields in Gjirokastra Region*
}

\section{Isidor Kokalari}

Department of Physics, University of Gjirokastra, Gjirokastra, Albania.

Email: ikokalari@uogj.edu.al

Received November $20^{\text {th }}, 2009$; revised January $12^{\text {th }}, 2010$; accepted January $18^{\text {th }}, 2010$.

\begin{abstract}
Nowadays, the increasing use of electric equipments (mobile phones, PC-s, home appliances, radio-TV, etc.), apart of their benefit, has raised the concern of possible health danger when it comes to non ionizing electromagnetic fields they emit. This paper is presenting the research done for the identification of the sources of such fields in the city of Gjirokastra, as well as for mapping the intensity of the field emitted. This study is mainly motivated by the absence of laws limiting field intensity in Albania and by the uncontrolled proliferation of emission sources. The position, the number and the different typologies of emitting sources are determined and afterwards, measurements of the intensity of these fields are done in the adjacency of the sources. Finally, the measured values were compared with the European limits of protection and the results of the measurements indicate that the level of exposure in this variety of sources is low.
\end{abstract}

Keywords: Electromagnetic Field, Electromagnetic Pollution, Health Effects, European Directive

\section{Introduction}

The use of computers and mobile phones are significant examples of the radical changes in our lifestyle by such technological breakthroughs of the last decades. This developments result on the increasing of occupational and public exposure to electromagnetic fields.

The increasing number of the sources of such fields, as well as controversies, often lacking scientific arguments, stimulates the misinformation on the actual status of research and achieved results. In the last years the public awareness towards possible health hazards related to the increasing exposure to non ionizing electromagnetic fields is growing continuously. In Gjirokastra town too, the so called electromagnetic pollution has attracted the attention of the local authorities and the inhabitants.

A great number of studies about possible hazardous effects of electromagnetic fields of high frequencies on human health, have given negative results [1-4]. Other epidemiologic studies about stimulation of leukaemia in children exposed to the low frequency fields, have given very contradictory evidence: some studies give negative $[5,6]$ and others give positive results $[7,8]$. Regardless all these, the exposure to non ionizing radiation is nowadays the main environmental and health concern.

The criterions used for health evaluation, are related to

*Paper publication sponsored by University of Gjirokastra, Albania the concepts of biological effect and health danger: the first happens when the interaction of the electromagnetic fields with human body produces a reaction by this latter and; usually the second is defined as a biological effect beyond the normal physiological compensation. This evaluation can be done using the guides based on EC/EU recommendations, which stimulate too the research in this area as well as the raise of public awareness. Two fundamental issues face each other: the public health care and technological progress. Hence, waiting the final results by scientific community on possible hazardous effects of non ionizing radiation, a special attention should be paid to the mechanisms of danger perception and to the ways to inform the public.

For Albania this is not one of the most urgent problem, however the state should adopt the European models of limiting the exposure to such radiation for the public [9] and workers [10]. That's why this study motivates the accomplishment of researches regarding the layout and intensity of electromagnetic fields.

\section{Materials and Methodology}

The results presented in this paper are the outcome of direct measurements of electric and magnetic fields of low frequencies $(50 \mathrm{~Hz})$ as well as those electromagnetic of high frequencies (RF). Initially, the number and the location of the sources of such fields were defined in 
Gjirokastra town (Figure 1) and the data on the technical parameters were collected. The direct measurements of these emitted fields are carried out near the power lines of high voltage, near radio base stations (RBS) of mobile telephony, near the antennas of radio-TV broadcasting, relaxing (bars, restaurants, etc.) and working places (power transforming stations, schools, etc.).

\subsection{Low Frequency Measurements}

\subsubsection{Places of Interest}

Power consumption, and the associated electromagnetic field levels, varies over time. The peak periods of power demand on the circuit are likely to be between 8:00 a.m. and 10:30 a.m. and between 4:30 p.m. and 6:30 p.m. Measurements are taken in two power supply stations in Gjirokastra town, near the transformers, generators, transforming cabins, working desk-places, outdoors and in the road passing near the stations. The new power station (built in 2007), is not yet working in its full capacity; while the old power station (built in the '70) provides the majority of power need for the town.

\subsubsection{Equipments Used for Measurements}

1) Anisotropic sensor for electric and magnetic fields ELF, model EMFields PRO. It has a digital readout and measures electric and magnetic fields with frequencies from 10 to $2000 \mathrm{~Hz}( \pm 3 \mathrm{~dB})$. The magnetic scale has a resolution of $0.01 \mu \mathrm{T}$ and a full scale of $19.99 \mu \mathrm{T}$. The electric scale has a resolution of $1 \mathrm{~V} / \mathrm{m}$ and a full scale of $1999 \mathrm{~V} / \mathrm{m}$ (with accuracy of $\pm 2 \%$ ). This hand-held instrument can be used, at home and in the workplace, to measure the fields from electric power sources-overhead

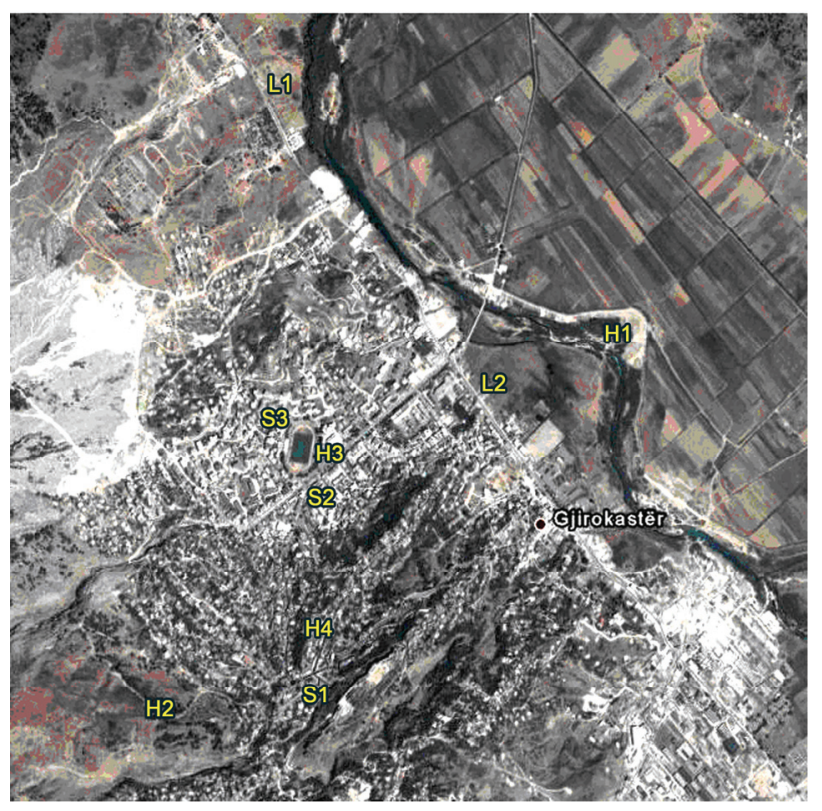

Figure 1. Satellite map of geographic distribution of the places where measurements are taken lines, substations, underground cables, house wiring, electrical appliances and equipment, etc.

2) Anisotropic sensor for magnetic fields ELF, model Chauvin-Arnoux CA40, Its frequency response range is $30 \mathrm{~Hz}-300 \mathrm{~Hz}$. The three scales and the respective accuracy in which this sensor can measure the values of magnetic inductance are: $0.01 \mu \mathrm{T}-20 \mu \mathrm{T}( \pm 4 \%) ; 0.1 \mu \mathrm{T}-$ $200 \mu \mathrm{T}( \pm 5 \%)$; and $1 \mu \mathrm{T}-2000 \mu \mathrm{T}( \pm 10 \%)$.

\subsection{High Frequency Measurements}

\subsubsection{Places of Interest}

Measurements of electromagnetic field intensity are taken near sources of various typologies which emit non ionizing radiations in the radio-frequency range, as well as in the vicinity of dwelling and relaxation places in the most exposed areas in Gjirokastra territory.

As the most suitable time to do the measurements are chosen the hours when the measured quantities reach their maximum values. In the case of radio base stations, the mornings of working days are selected (09:00-13:00), which is the time of the greatest use of mobile phones; meanwhile for the sources of radio-TV broadcasting, evening is selected in the interval 19:00-21:00 hrs.

Measuring process generally took an interval of one hour, after which, based on the collected data, the 6 minutes period in which the fields reached the maximum values is selected to be target of analysis.

The places selected for the measurements, besides their geographic distribution in the town, present a significantly dense number of the sources, or are populated for more than four hours per day (schools: S1, S2, S3; working $\mathrm{H} 1, \mathrm{H} 2$; and relaxing places: H3, H4). Generally, as measuring spots are chosen the ones with the greatest coverage by the cone of the field emitted by the source. First measurements of the intensity of electric component $(E)$ of the field of frequency in the range of radio- and micro-waves, as well as of the power density $(S)$, are taken in various spots of Gjirokastra town, in highly attended places by public and/or near small RBS-s.

Later measurements are carried out in St.Triadha Mountain (Figure 2(a)), facing the town, a few kilometres from national road, in the vicinity of three radio-base stations (RBS) of three mobile phone operators. It is worth to emphasize the fact that the third RBS in this spot is built up recently (about seven months ago), after the third mobile telephony operator entered the market.

Other measurements are taken in Këculla hill (Figure 2(b)), a high altitude place overlooking Gjirokastra town, which is the site of many RBS-s for mobile telephony and antennas for radio-TV broadcasting. Such spot is almost visible by every point of the town.

\subsubsection{Equipments Used for Measurements}

Isotropic sensor for radio-frequencies, model ChauvinArnoux CA43, operative in the frequency range between 
$100 \mathrm{kHz}$ and $2.5 \mathrm{GHz}$. The sensor is capable to measure values of electric field from $0.1 \mathrm{~V} / \mathrm{m}$ to $199.9 \mathrm{~V} / \mathrm{m}$ with a resolution of $0.1 \mathrm{~V} / \mathrm{m}$ and accuracy $1 \mathrm{~dB}$. It can measure also the power density between $0.1 \mu \mathrm{W} / \mathrm{cm}^{2}$ and 1999 $\mu \mathrm{W} / \mathrm{cm}^{2}$; with resolution $0.1 \mu \mathrm{W} / \mathrm{cm}^{2}$ and accuracy $1 \mathrm{~dB}$ in the range $0.1-199.9 \mu \mathrm{W} / \mathrm{cm}^{2}$ and, with resolution 1 $\mu \mathrm{W} / \mathrm{cm}^{2}$ and accuracy $2 \mathrm{~dB}$ in the range $200-1999$ $\mu \mathrm{W} / \mathrm{cm}^{2}$. It is capable also to store data in a PC (Figure 3).

\section{Results and Discussions}

\subsection{Low Frequency Fields}

The old power station, located in the entrance of the town (L2), is identified as one of the sources emitting low frequency radiation. Meanwhile, in the suburbs of Gjirokastra is functioning, still with reduced capacity, another transforming station (L1) transforming from $110 \mathrm{kV}$ to $20 \mathrm{kV}$. It is worth emphasizing the great evident difference of the respective technologies and equipments used in these two stations, which obviously influences the exposure level of the working staff.

Measurements are done indoor of each station, where the employees spend most of the time and the European guides [11] are taken as reference. Maximal values, correspond to the measures in the vicinity $(\sim 30 \mathrm{~cm})$ of the transformers.

Values presented in Table 1 (L1-for the new station; L2-for the old one) show the maximum of the intensity of the magnetic field. From health effect point of view, this is the quantity to be more attentively considered regarding the low frequencies range.

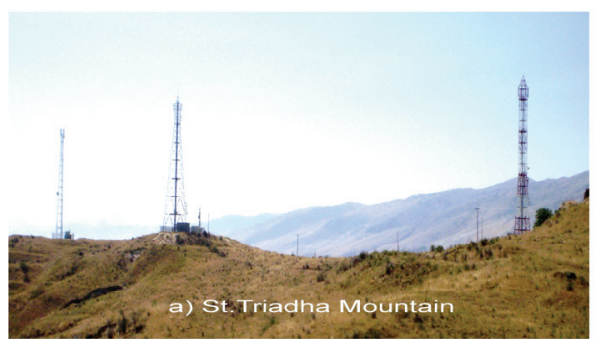

(a)

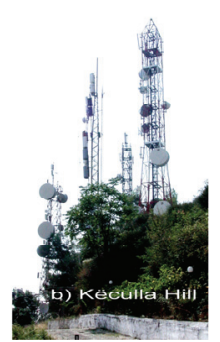

(b)
Figure 2. High frequency radiation sources (a) St.Triadha mountain (b) Këculla hill

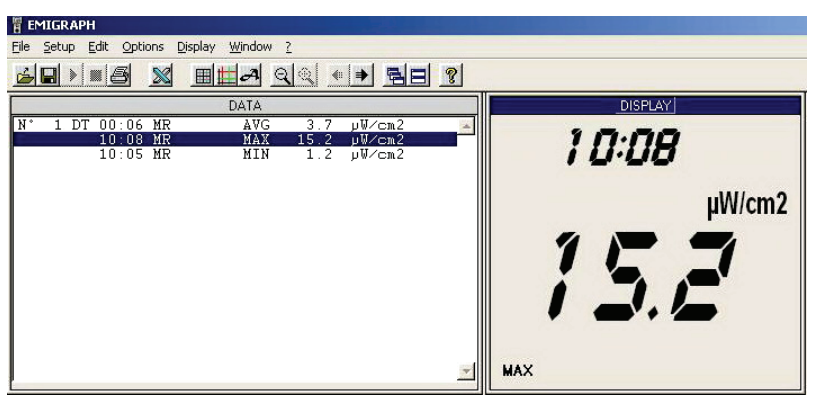

Figure 3. Maximal power density value at bar "First" (H3)
Table 1. Magnetic inductance in the new (L1) and old (L2) power transforming stations in Gjirokastra

\begin{tabular}{lcc}
\hline Place of measurement & $\begin{array}{c}L 1 \\
B_{\max }(\mu \mathrm{T})\end{array}$ & $\begin{array}{c}L 2 \\
B_{\max }(\mu \mathrm{T})\end{array}$ \\
\hline Staff room (control panel) & 0.06 & 0.68 \\
Outdoor transformers & 5.71 & 72.6 \\
Outdoor control cabin & 0.16 & 7.12 \\
Main entrance (next to the road) & 0.31 & 0.45 \\
\hline
\end{tabular}

\subsection{High Frequency Fields}

Measurements of the intensity of RF electromagnetic fields are done in the St.Triadha mountain (H1) where in front of Gjirokastra town are positioned three RBS-s of mobile telephony (Figure 2(a)); in Këculla (H2) hill near four pillars with a great number of antennas of various typologies: radio-TV broadcasting and RBS-s (Figure 2(b)) and in other places in the town as shown in Table 2.

Measurements are taken in accordance with European guides [12]. The use of spectrum analyser is not considered necessary because the measured values result lower than respective European limits.

Maximal measured values of the intensity of electric field and power density are presented in Table $\mathbf{2}$ where only the $E(\mathrm{~V} / \mathrm{m})$ is shown, because the values of magnetic inductance are easily calculated by $B=E / c \quad$ [13].

\section{Conclusions}

By the measurements done for the fields of low frequency $(50 \mathrm{~Hz})$ in two electrical power stations, the electric and magnetic fields result with values below the occupational limits $(500 \mu \mathrm{T})$ of European directives for the places occupied more than 4 hours per day. The greatest values are recorded in the vicinity of the transformers, but these are places where workers stay for only a few minutes for maintenance purposes. Values measured in the new station (L1), much smaller than in the old one (L2), can be explained with the new modern equipments used there and with the reduced capacity that the station is working currently.

Regarding the high frequency emissions, despite the great number of the sources and their typology, the electromagnetic field results with values in consistency with the EU directives for places permanently populated. This can be easily verified by comparing the measured values (Table 2) with limits presented in Table 3 [14].

Even in the case of bar "First" where the clients are practically under a RBS, the measured values are small enough as not to present a worry about health effects for the staff and even less for the clients of the bar. 
Table 2. Maximal values of electric field intensity $\mathrm{E}$, and power density $S$

\begin{tabular}{llcc}
\hline & Place of measurement & $\begin{array}{c}E_{\max } \\
(\mathrm{V} / \mathrm{m})\end{array}$ & $\begin{array}{c}S_{\max } \\
\left(\mathrm{W} / \mathrm{m}^{2}\right)\end{array}$ \\
\hline H1 & St. Triadha mountain (RBS) & 6.3 & 0.119 \\
H2 & Këculla hill (RBS, TV) & 9.1 & 0.162 \\
H3 & Terrace of bar "First" (RBS) & 4.5 & 0.152 \\
H4 & Restaurant "Fantazia" & 2.4 & 0.008 \\
S1 & High School "H. Tahsin" & 1.2 & 0.003 \\
S2 & Elementary School "K. Hoxhi” & 0.9 & 0.002 \\
S3 & University of Gjirokastra & 1.6 & 0.006 \\
\hline
\end{tabular}

Table 3. European public and occupational limits for exposure to high frequency fields [14]

\begin{tabular}{cccccc}
\hline \multicolumn{2}{c}{ limits for public } & \multirow{2}{*}{ frequency $\boldsymbol{f}$} & \multicolumn{2}{c}{ limits for workers } \\
\cline { 1 - 1 } \cline { 5 - 6 }$(\mathrm{V} / \mathrm{m})$ & $S\left(\mathrm{~W} / \mathrm{m}^{2}\right)$ & & $E(\mathrm{~V} / \mathrm{m})$ & $S\left(\mathrm{~W} / \mathrm{m}^{2}\right)$ \\
\hline 28 & 2 & $10-400 \mathrm{MHz}$ & 61 & 10 \\
$1,375 f^{1 / 2}$ & $f / 200$ & $400-2000 \mathrm{MHz}$ & $3 f^{1 / 2}$ & $f / 40$ \\
61 & 10 & $2-300 \mathrm{GHz}$ & 137 & 50 \\
\hline
\end{tabular}

\section{Acknowledgements}

Work supported by the bilateral research project "Analysis of the intensity of electric and magnetic fields at 50 $\mathrm{Hz}$ and of the electromagnetic field in the range $100 \mathrm{kHz}-$ $3 \mathrm{GHz}$ and of their origin" implemented by the Physics Departments of Salento (Italy) and Gjirokastra (Albania) Universities, coordinated by prof. A.Luches and prof. V.Bakuli, financed by the Italian Ministry of Foreign Affairs and the Albanian Ministry of Education and Science.

\section{REFERENCES}

[1] N. A. Cridland, "Electromagnetic Fields and Cancer: A Review of Relevant Cellular Studies," Chilton, National Radiological Protection Board, London, 1993.

[2] B. Kallen, G. Malmquist and U. Moritz, "Delivery Outcome among Physiotherapists in Sweden: Is Non-Ionizing Radiation a Fetal Hazard," Archives of Environmental Health, Vol. 37, No. 2, 1982, pp. 81-85.
[3] "Electromagnetic Fields and the Risk of Cancer: Report of an Advisory Group on Non-Ionising Radiation," Documents of the National Radiation Protection Board, Vol. 3, No. 1, 1992, pp. 1-138.

[4] "Electromagnetic Fields $(300 \mathrm{~Hz}$ to $300 \mathrm{GHz}), "$ Environmental Health Criteria, World Health Organization, Geneva, No. 137, 1993.

[5] M. S. Linet, E. E. Hatch, R. A. Kleinerman, L. L. Robison, W. T. Kaune, D. R. Friedman, R. K. Severson, C. M. Haines, C. T. Hartsock, S. Niwa, S. Wacholder and R. E. Tarone, "Residential Exposure to Magnetic Fields and Acute Lymphob-Lastic Leukaemia in Children," New England Journal of Medicine, Vol. 337, No. 1, 1997, pp. $1-7$.

[6] M. L. McBride, R. P. Gallagher, G. Thériault, B. G. Armstrong, S. Tamaro, J. J. Spinelli, J. E. Deadman, B. Fincham, D. Robson and W. Chaoi, "Power-Frequency Electric and Magnetic Fields and Risk of Childhood Leukaemia in Canada," American Journal of Epidemiology, Vol. 149, No. 9, 1999, pp. 831-842.

[7] "Possible Health Effects of Exposure to Electric and Magnetic Fields," National Academy Press, National Academy of Sciences/National Research Council, Washington DC, 1996.

[8] N. Wertheimer and E. Leeper, "Electrical Wiring Configurations and Childhood Cancer," American Journal of Epidemiology, Vol. 109, No. 3, 1979, pp. 273-284.

[9] “Directive 1999/ 519/CE, 12 July 1999," Official Journal of European Community, European Union Parliament and Council, Vol. 30, No. 7, 1999, pp. (L199)59-70.

[10] “Directive 2004/40/CE, 29 April 2004," Official Journal of European Community, European Union Parliament and Council, Vol. 24, No. 5, 2004, pp. (L184)1-9.

[11] "Measurement of Low- Frequency Magnetic and Electric Fields with Regard to Exposure of Human Beings-Special Requirements for Instruments and Guidance for Measurements", International Standard CEI 61786, 1998.

[12] "Measurement of Exposure to Radiofrequency Electromagnetic Fields-Field Strength in the Frequency Range 100KHz-1GHz," Health Physics, International Standard CEI 61566, Vol. 74, No. 4, 1998, pp. 494-522.

[13] I. Kokalari, "Metodika e Vlerësimit të Ekspozimit Ndaj fushave Elektromagnetike jo Jonizuese," Matematika dhe Shkencat e Natyrës, Kërkime Universitare, Vol. 15, 2007, pp. 54-67.

[14] "Guidelines for Limiting Exposure to Time-Varying Electric, Magnetic and Electromagnetic Fields (Up To 300 GHz)," Health Physics, International Commission on Non-Ionizing Radiation Protection, Vol. 74, No 4, 1998, pp. 494-522. 